\title{
Geometry and Topology of Submanifolds IX
}


This page is intentionally left blank 


\section{Geometry \\ and Topology \\ of Submanifolds IX}

Dedicated to Professor Radu Rosca on

the Occasion of his 90th Birthday

Valenciennes, France

26 - 27 March 1997

Lyon, France

17 - 18 May 1997

Leuven, Belgium

18 - 20 September 1997

Editors

F. Defever

Katholieke Universiteit Leuven, Belgium

J. M. Morvan

Université Claude Bernard Lyon 1, France

I. Van de Woestijne

Katholieke Universiteit Brussel, Belgium

L. Verstraelen

Katholieke Universiteit Leuven and

Katholieke Universiteit Brussel, Belgium

G. Zafindratafa

Université de Valenciennes et du Hainaut-Cambrésis, France 


\section{Published by}

World Scientific Publishing Co. Pte. Ltd.

P O Box 128, Farrer Road, Singapore 912805

USA office: Suite 1B, 1060 Main Street, River Edge, NJ 07661

UK office: 57 Shelton Street, Covent Garden, London WC2H 9HE

\section{British Library Cataloguing-in-Publication Data}

A catalogue record for this book is available from the British Library.

\section{GEOMETRY AND TOPOLOGY SUBMANIFOLDS IX}

Copyright () 1999 by World Scientific Publishing Co. Pte. Ltd.

All rights reserved. This book, or parts thereof, may not be reproduced in any form or by any means, electronic or mechanical, including photocopying, recording or any information storage and retrieval system now known or to be invented, without written permission from the Publisher.

For photocopying of material in this volume, please pay a copying fee through the Copyright Clearance Center, Inc., 222 Rosewood Drive, Danvers, MA 01923, USA. In this case permission to photocopy is not required from the publisher.

ISBN 981-02-3897-5

Printed in Singapore by Regal Press (S) Pte. Ltd. 


\section{PREFACE}

This volume collects papers on a number of talks given at our 1997 meetings at Valenciennes in March, at Lyon in May, and at Leuven in September, and the Wrocław satellite meeting in connection with this latter one, and also the continuation by Udo Simon et al. of the ADG-bibliography started in Volume 8.

I heartily thank G. Zafindratafa, J. M. Morvan, F. Dillen, and R. Deszcz for their work in the organization of these meetings at Valenciennes, Lyon, Leuven and Wrocław, respectively, and the Department of Mathematics of their universities for their support in various ways which were essential to make these meetings possible. Together with F. Dillen and I. Van de Woestijne, and on behalf of PADGE, our Centre for Pure and Applied Differential Geometry, I want to thank the Research Councils of both the K.U. Leuven and the K.U. Brussels for their financial support for our research work in general, and also for these meetings in particular, and also the Agriculture University of Wrocław for its support to the local PADGE division headed by R. Deszcz.

I would also like to thank the French Embassy at Brussels for their support of the scientific cooperation of PADGE with geometers of Valenciennes, Lyon, and Paris, and also the Tournesol program for the support of cooperation between the K.U. Leuven and the University of Valenciennes.

This Volume 9 is respectfully dedicated to Professor Radu Rosca on the occasion of his 90th birthday. Almost 30 years ago, at Bucharest, I had the good fortune to be initiated by him to research in differential geometry, and ever since then we always stayed in close scientific and social contact. His dramatic life of continuous work devoted unselfishly to science and humanity sets an example for us all!

Leopold Verstraelen

Leuven, April 14, 1999 
This page is intentionally left blank 


\section{CONTENTS}

Preface

Affine Bibliography 1998

T. Binder, U. Simon and M. Wiehe

Contact Metric $R$-Harmonic Manifolds

$K$. Arslan and C. Murathan

Curves and Surfaces of $A W(k)$ Type

K. Arslan and C. Özgür

Local Classification of Centroaffine Tchebychev Surfaces

with Constant Curvature Metric

T. Binder

Polar Hypersurfaces in Spheres

F. Brito, H. L. Liu, V. I. Oliker, U. Simon

and $C$. P. Wang

Hypersurfaces in Space Forms with Some Constant

Curvature Functions

F. Brito, H. L. Liu, U. Simon and C. P. Wang

Some Relations Between a Submanifold and Its Focal Set

S. Carter and A. West

On the Lagrangian Catenoid

I. Castro

New Types of Riemannian Curvature Invariants and Their Applications

B. $-Y$. Chen

On Manifolds of Pseudosymmetric Type

F. Defever, R. Deszcz, M. Hotloś, M. Kucharski

and Z. Sentürk 
viii

Hypersurfaces with Pseudosymmetric Weyl Tensor in

Conformally Flat Manifolds

R. Deszcz, L. Verstraelen and S. Yaprak

Least-Squares Geometrical Fitting and Minimising Functions on Submanifolds

F. Dillen, M. Janssens, J.-P. Kruth, P. Vanherck

and $L$. Verstraelen

Curvature of Ruled Surfaces and Groups of Lorentzian Motions

F. Dillen and W. Kühnel

On the Problem of Modified Theory of Invariant Variation Problems Construction

K. G. Garaev

A Curvature Inequality for Riemannian Submanifolds in

a Semi-Riemannian Space Form

B. Gmira and L. Verstraelen

Cubic Forms Generated by Functions on Projectively Flat Spaces

J. Leder

Generating Higher Order Codazzi Tensors by Functions

J. Leder, A. Schwenk-Schellschmidt, U. Simon and M. Wiehe

Distinguished Submanifolds of a Sasakian Manifold

I. Mihai

On the Curvature of Left Invariant Locally Conformally

Para-Kählerian Metrics

Z. Olszak

Examples of Weyl Geometries in Affine Differential Geometry M. Peikert

Remarks on Affine Variations on the Ellipsoid M. Wiehe

Dirac's Equation, Schrödinger's Equation and the Geometry of Surfaces

T. J. Willmore 